\title{
柴达木盆地尔斯库勒盐湖地表水一地下水的转化与铀的补给通量”
}

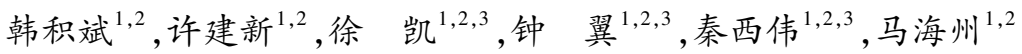 \\ (1: 中国科学院青海盐湖研究所, 中国科学院盐湖资源综合高效利用重点实验室, 西宁 810008) \\ (2: 青海省盐湖地质与环境重点实验室,西宁 810008) \\ (3: 中国科学院大学,北京 100049)
}

\begin{abstract}
摘 要: 流域范围内地表水和地下水转化对盐湖成盐元素的运移和富集具有十分重要的意义. 本文通过尔斯库勒盐湖盆 地内流域水体的水化学和 $\mathrm{B}$ 同位素特征识别了地表水和地下水之间的定量转化关系,在此基础上估算了流域中铀的补 给通量. 结果表明, 流域水体中离子的分异除了蒸发浓缩作用之外, 还受重力分异及掺杂作用的影响; 上游库拉木勒克萨 伊河和阿特阿特坎河水体在出山口附近转人地下并在中游补给地表水和地下水,其补给率分别占 $48.8 \%$ 和 $51.2 \%$,年均 补给量分别为 $1.08 \times 10^{8}$ 和 $1.13 \times 10^{8} \mathrm{~m}^{3} / \mathrm{a}$; 在中游至尾问盐湖段, 阿拉尔河和侧向补给对盐湖卤水的补给率占 $55.2 \%$, 深 部水体的补给占 $44.8 \%$; 至少从 $5.7 \mathrm{ka}$ 以来, 上游水体对盐湖卤水中铀的补给通量为 $4.11 \times 10^{3} \mathrm{t}$, 在湖积平原黏土沉积带 以及祁漫塔格山前局部还原带可能具有较大规模的铀矿. 研究结果有助于建立盐湖盆地水循环模式、揭示卤水资源形成 机制 ; 同时为尔斯库勒盐湖盆地水资源的高效利用和寻找铀矿提供理论依据和技术支持.
\end{abstract}

关键词 : 地表水与地下水;转化关系;铀通量;找矿意义;尔斯库勒盐湖盆地

\section{The exchange relationship of surface water-groundwater and uranium flux in the Gas Hure Salt Lake of northwest Qaidam Basin, China}

\author{
HAN Jibin ${ }^{1,2}$, XU Jianxin ${ }^{1,2}$, XU Kai ${ }^{1,2,3}$, ZHONG Yi ${ }^{1,2,3}$, QIN Xiwei ${ }^{1,2,3}$ \& MA Haizhou ${ }^{1,2}$ \\ (1: Key Laboratory of Comprehensive and Highly Efficient Utilization of Salt Lake Resources, Qinghai Institute of Salt Lakes, \\ Chinese Academy of Sciences, Xining 810008, P.R.China) \\ (2: Qinghai Provincial Key Laboratory of Geology and Environment of Salt Lakes, Xining 810008, P.R. China) \\ (3: University of Chinese Academy of Sciences, Beijing 100049, P.R.China)
}

\begin{abstract}
Surface water and groundwater exchanging is of great significance for elements migration and enrichment of salt lakes in Qaidam Basin. The paper focus on the exchanging relationship between surface water and groundwater quantitatively and evaluating the uranium recharge flux in the Gas Hure Salt Lake Basin with the use of an integrated approach including hydrochemistry and boron isotope. The results indicate that the ion differentiation phenomenon is controlled not only by the evaporation, but also by the gravitative differentiation and migmatization. Along the flow direction of the basin, the surface water and groundwater have a tight hydraulic connection with each other, they have been transformed two times. In the upper reach, the Kulamuleksay River and Ateatekan River are recharged into the surface water and groundwater in the middle reach with the ratios being $48.8 \%$ and $51.2 \%$, and the annual supply being $1.08 \times 10^{8} \mathrm{~m}^{3} / \mathrm{a}$ and $1.13 \times 10^{8} \mathrm{~m}^{3} / \mathrm{a}$, respectively. From the middle reach to the lower reach, the contribution ratios of the Aler River and lateral flow being 55.2\%, and the deep groundwater flow being $44.8 \%$, respectively. During the $5.7 \mathrm{ka}$, the upper reach river water has been supplied $4.11 \times 10^{3}$ tons uranium in the salt lake, and in the middle reach, which can be likely to reserving uranium because of clay adsorption and redox precipitation at the lacustrine plain and the Qimantage mountain front. This study could provide theoretical basis and technical support for setting up hydrologic cycle of salt lake basin, revealing the formation mechanism of brine resources, highly efficient utilizing water resources, and for prospecting uranium.
\end{abstract}

Keywords: Surface water and groundwater; exchanging relationship; uranium flux; prospecting significance; Gas Hure Salt Lake Basin

* 中国科学院 “西部之光”项目 (Y910061016) 和青海省科技厅项目 (2019-ZJ-7028) 联合资助. 2018-12-24 收稿; 2019-04-22 收修改稿. 韩积斌( 1985 ）, 男,博士, 助理研究员; E-mail: jbhan@ isl.ac.cn. 
河流与地下水的转化是流域水循环研究的关键环节 ${ }^{[1]}$. 查明地表水与地下水的转化关系, 对建立流域 水循环模式, 研究水资源的形成、演化,揭示水循环机理, 实现流域水资源高效利用, 维持河流生态系统等具 有重要的理论和现实意义 ${ }^{[2]}$. 盐湖是湖泊演化的晚期阶段, 它广泛分布于极端干旱区, 盐湖区水资源极其员 乏, 且分布十分不均匀. 近年来, 盐湖资源大规模开发利用过程中对淡水和卤水资源的需求量不断增加, 导 致盐湖区水一盐均衡被破坏 ${ }^{[3-4]}$. 这些问题的产生, 归根结底是没有弄清楚盐湖盆地水循环的机理, 没有定量 地认识到地表水和地下水对盐湖的水量补给, 以及没有掌握补给水量与盐类矿物形成所需水量之间的均衡 关系, 从而造成盐湖资源严重浪费和高值元素 ( $\mathrm{Li} 、 \mathrm{~B} 、 \mathrm{U}$ 等) 严重流失 ${ }^{[5-6]}$. 因此, 上述问题在盐湖资源大规模 开发利用过程中函待解决.

基于此, 我们选取柴达木盆地西北部的尔斯库勒盐湖为例, 该盐湖具有开发强度低、人为干扰较小、卤 水中富铀等特点, 对研究盐湖盆地地表水一地下水之间的转化关系具有代表性. 在过去的研究中针对盐湖区 水循环的研究鲜有报道, 也没有引起重视. 近年来, 学者们开始认识到水循环对盐湖成盐成矿具有十分重要 的影响, 并尝试在察尔汗盐湖、东一西台吉乃尔盐湖区开展水循环研究 ${ }^{[7-8]}$. 我们在尔斯库勒盐湖区初步识别 了地表水和地下水之间的水力联系 ${ }^{[9]}$, 以及铀的来源和迁移富集规律 ${ }^{[10-12]}$. 但上述成果没有定量地研究区 域水循环的补给转化关系, 也没有定量地研究有益组分的补给通量. 因此, 本文利用传统的水化学法结合 B 同位素技术, 定量地查明盐湖盆地地表水一地下水的转化关系, 估算二者对盐湖卤水的补给量, 在此基础上 估算铀的补给通量. 本研究为盐湖区水资源的高效利用和水盐均衡理论提供科学依据, 同时为进一步圈定 铀矿靶区提供技术支持.

\section{1 研究区水文地质}

尔斯库勒盐湖盆地位于柴达木盆地西北部, 盆地北部为阿尔金山, 最高海拔为 $4790 \mathrm{~m}$, 南为祁漫塔格 山, 海拔为 4000 4500 m, 东北部为油砂山, 海拔为 3200 3600 m, 尔斯库勒盐湖位于盆地的中央低洼地带, 海拔为 $2860 \mathrm{~m}$. 盆地内主要的常年性河流为上游的库拉木勒克萨伊河 (KLMH) 和阿特阿特坎河 (ATKH), 两 条河流在出山口转人地下, 并在中游溢出地表形成泉集河 (ALEH 河), 最终直接汇人尔斯库勒盐湖. 盆地内 气候类型从上游至下游具有明显的分带特征, 上游为高寒山区, 年均气温 $0^{\circ} \mathrm{C}$ 以下, 年降水量 $300 \mathrm{~mm}$ 左右; 中游和下游盛行西北风, 最大风速 $23.3 \mathrm{~m} / \mathrm{s}$, 年平均气温 $1.53^{\circ} \mathrm{C}$, 最高月平均气温 $13.3^{\circ} \mathrm{C}(7-8$ 月), 最低月 平均气温 $-12.1^{\circ} \mathrm{C}$ ( 1 月), 日温差高达 $29 \sim 32^{\circ} \mathrm{C}$. 中游和下游属于极端干旱区, 年降水量分别为 $137.1 、 55.3$ $\mathrm{mm} / \mathrm{a}$; 年蒸发量分别为 $1208.5 、 2856.9 \mathrm{~mm} / \mathrm{a}^{[13]}$.

盆地属于典型的山间地貌类型, 从上游至下游总体上可分为侵蚀构造中高山、剥蚀构造中低山、冲洪积 平原、冲湖积平原. 受新构造运动的控制, 河流中游至下游沉积了巨厚的第四系碎屑一含盐系沉积物. 研究 区出露的古生界岩层分布于阿尔金山及祁漫塔格山, 岩性以花岗岩、花岗闪长岩等超基性岩为主; 中生界地 层出露于阿尔金山南坡, 岩性以砾岩、砂岩、页岩为主; 新生界地层主要分布于冲积扇前平原及盐湖矿区东 北部的禇皱构造带, 岩性为粉砂岩、泥岩、石盐、石膏等 ${ }^{[14]}$.

盆地内地下水类型为松散岩类孔隙潜水和松散岩类孔隙承压水 ${ }^{[13]}$. 高山区主要为基岩裂隙水, 在祁漫 塔格山前和 ALEH 河两侧的河漫滩主要为松散岩类孔隙潜水 (淡水), 为地下水富水区. 尔斯库勒湖积平原 以西地带, 由于地形坡度逐渐减小, 水动力条件由强变弱, 地下水类型逐渐过渡为承压水; 湖积平原以东地 带, 主要赋存化学岩类晶间卤水. 潜晶间卤水水位埋深浅, 富水性强; 晶间承压卤水水位埋深在 $10 \sim 20 \mathrm{~m}$.

\section{2 研究方法}

在 2015 年 5-6 月, 沿着 KLMH 流域开展野外调查和采样工作, 共采集地表水样 31 组: 其中河流上游段 (图 1a) 采集 KLMH 水样 10 组、ATKH 水样 4 组, 河流上游段未采集地下水样品; 河流中游段 (图 1b) 采集 ALEH 水样 3 组、溪水 4 组; 河流下游一尾问盐湖段 (图 $1 \mathrm{~b}$ ) 采集湖表卤水 10 组; 整个流域中采集浅层 (潜水) 地下水样 23 组: 包括中游段泉水 10 组、井水 2 组; 采集下游段晶间卤水 11 组,采样点分布如图 1 所示. 利用 多功能水质参数仪 YSI ( Professional Plus 6050000, USA) 现场原位测定水体的 $\mathrm{pH}$ 和总溶解固体 (TDS) 浓度. 样品均在现场过 $0.45 \mathrm{~mm}$ 的滤膜, 然后置于清洗干净的 $500 \mathrm{ml}$ 聚乙烯采样瓶中, 并尽量保证水样装满采样 
瓶, 防止瓶内产生气泡. 在测定 $\mathrm{U}$ 元素的样品中加人优级纯硝酸使水样的 $\mathrm{pH}$ 值小于 2 , 然后用胶带密封并 尽快运往室内实验室进行常量元素和同位素组成分析.
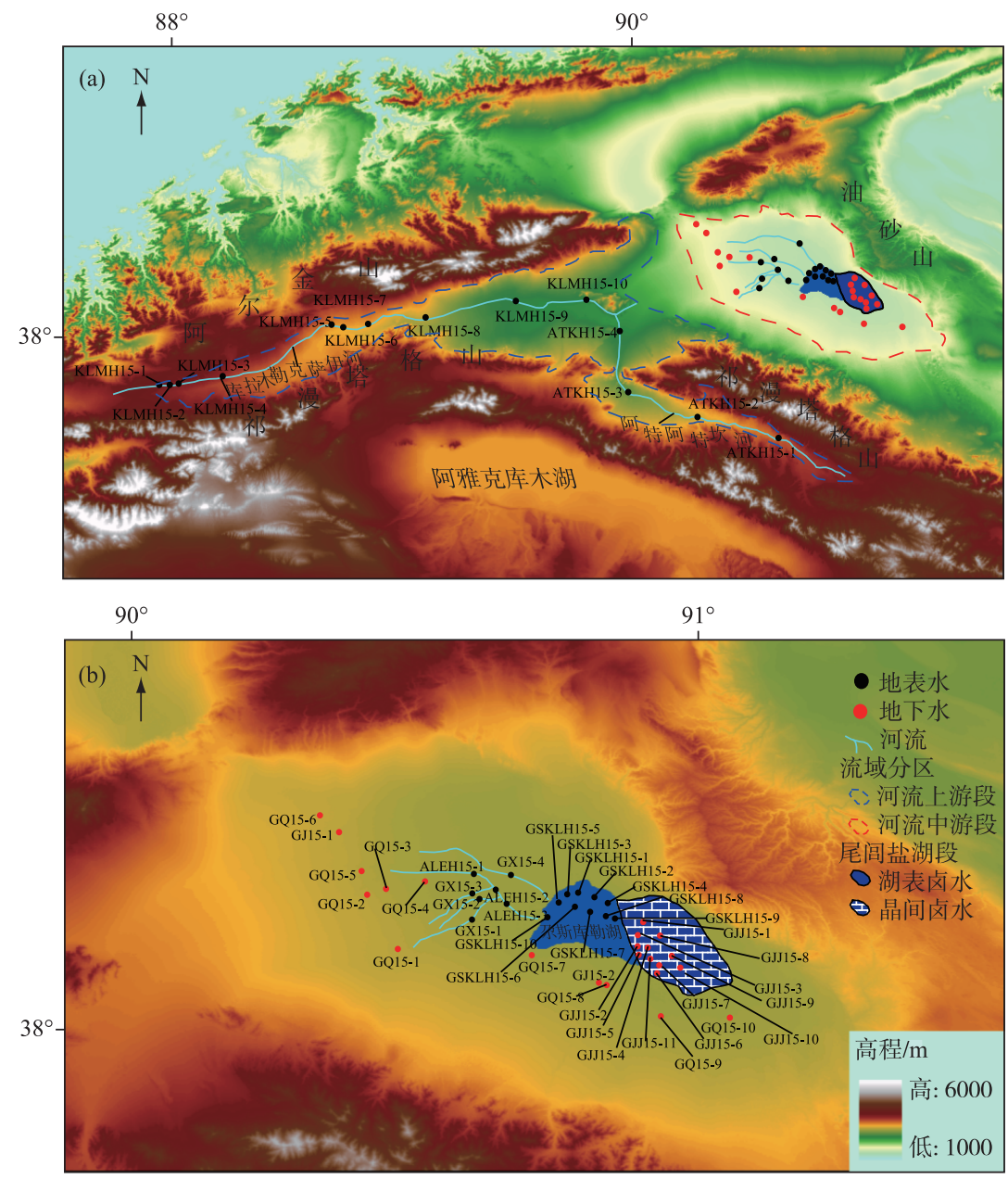

图 1 尔斯库勒盐湖位置及采样点

Fig.1 Location and water sampling sites of the Gas Hure Salt Lake Basin

常量元素和 B 同位素的测定在中国科学院青海盐湖研究所盐湖化学分析测试中心完成. 利用 ICP-OES (IRIS Intrepid II XSP, Thermo Elemental, Madison, WI, USA) ( error $< \pm 1 \%$ ) 测定 $\mathrm{Ca}^{2+}, \mathrm{Mg}^{2+}, \mathrm{Na}^{+}, \mathrm{K}^{+}, \mathrm{B}^{3+}$ 浓度; 利用离子色谱 (Dionex 120, Dionex, Sunnyvale, CA, USA) (error $< \pm 5 \%$ ) 测定 $\mathrm{SO}_{4}^{2-}$ 和 $\mathrm{Cl}^{-}$浓度; 利用盐酸滴定法 测定 $\mathrm{HCO}_{3}^{-}$和 $\mathrm{CO}_{3}^{2-}$ 浓度 $($ error $< \pm 1 \%$ ); 采用 ICP-MS (PerkinElmer ELAN DRC- II ) (error $< \pm 5 \%$ ) 测定 U 浓度; 采用 TIMS ( NIST SRM 951) ( error $< \pm 0.3 \%$ ) 对部分水样测定 B 同位素. 测试结果如表 1 所示.

\section{3 结果}

\section{1 盆地内水体的水化学特征}

在河流上游, 地表水的 $\mathrm{pH}$ 变化范围为 $8.01 \sim 8.93$, 平均值为 8.29 , 为弱碱性水体; TDS 浓度变化范围为 $0.33 \sim 1.05 \mathrm{~g} / \mathrm{L}$, 平均值为 $0.50 \mathrm{~g} / \mathrm{L}$; 在河流中游, 地表水和地下水的 $\mathrm{pH}$ 变化范围分别为 $8.10 \sim 8.40 、 7.80 \sim$ 8.30 , 平均值分别为 8.26 和 8.13 , 为弱碱性水体; TDS 浓度变化范围分别为 $0.84 \sim 14.85 、 0.30 \sim 6.49 \mathrm{~g} / \mathrm{L}$, 平均 值分别为 $3.52 、 1.67 \mathrm{~g} / \mathrm{L}$, 均为咸水; 在河流下游一尾问湖段, 湖表卤水和晶间卤水的 $\mathrm{pH}$ 变化范围分别为 
$7.70 \sim 7.80 、 6.20 \sim 7.80$, 平均值分别为 7.76、7.21, 呈中性或弱碱性; TDS 浓度变化范围为 228.11 243.51、 $126.38 \sim 397.61 \mathrm{~g} / \mathrm{L}$, 平均值分别为 $236.45 、 319.08 \mathrm{~g} / \mathrm{L}$, 为高矿化度卤水.

表 1 尔斯库勒盐湖盆地水体的水化学和同位素统计结果

Tab.1 Statistical values for the chemical and boron isotopic compositions of water samples collected in the Gas Hure Salt Lake Basin

\begin{tabular}{|c|c|c|c|c|c|c|c|c|c|c|c|c|c|c|c|c|}
\hline \multirow{2}{*}{\multicolumn{2}{|c|}{ 流域 类型 }} & \multirow{2}{*}{$\begin{array}{l}\text { 样品 } \\
\text { 数 }\end{array}$} & \multirow{2}{*}{$\begin{array}{l}\text { 统计 } \\
\text { 值 }\end{array}$} & \multirow{2}{*}{$\mathrm{pH}$} & \multirow{2}{*}{$\begin{array}{l}\text { TDS/ } \\
(\mathrm{g} / \mathrm{L})\end{array}$} & \multirow{2}{*}{$\begin{array}{c}\mathrm{U} / \\
(\mathrm{mg} / \mathrm{L})\end{array}$} & \multicolumn{8}{|c|}{ 水化学/ $(\mathrm{mg} / \mathrm{L}){ }^{*}$} & \multicolumn{2}{|c|}{ 同位素 } \\
\hline & & & & & & & $\mathrm{Ca}^{2+}$ & $\mathrm{Mg}^{2+}$ & $\mathrm{Na}^{+}$ & $\mathrm{K}^{+}$ & $\mathrm{HCO}_{3}^{-}$ & $\mathrm{SO}_{4}^{2-}$ & $\mathrm{Cl}^{-}$ & $\mathrm{B}^{3+}$ & 样品数 & $\delta^{11} \mathrm{~B} / \%$ \\
\hline \multirow[t]{3}{*}{ 上游 } & 地表 & 14 & 最小值 & 8.01 & 0.33 & 2.09 & 30 & 10 & 10 & 2.65 & 90 & 50 & 60 & 0.02 & 6 & 6.23 \\
\hline & 水 & & 最大值 & 8.93 & 1.05 & 15.21 & 90 & 50 & 140 & 11.28 & 370 & 220 & 180 & 0.43 & & 8.03 \\
\hline & & & 平均值 & 8.29 & 0.50 & 6.23 & 50 & 20 & 70 & 4.51 & 150 & 100 & 110 & 0.13 & & 7.30 \\
\hline \multirow[t]{6}{*}{ 中游 } & 地表 & 7 & 最小值 & 8.1 & 0.84 & 4.43 & 60 & 30 & 150 & 6.78 & 260 & 160 & 170 & 0.33 & 2 & 15.85 \\
\hline & 水 & & 最大值 & 8.4 & 14.85 & 175.1 & 320 & 560 & 3890 & 144.5 & 440 & 5560 & 3940 & 3.49 & & 17.14 \\
\hline & & & 平均值 & 8.26 & 3.52 & 46.75 & 136 & 140 & 829 & 34.72 & 32 & 1106 & 950 & 1.01 & & 16.50 \\
\hline & 地下 & 12 & 最小值 & 7.8 & 0.30 & 7.59 & 20 & 20 & 50 & 2.77 & 11 & 60 & 50 & 0.14 & 6 & 8.05 \\
\hline & 水 & & 最大值 & 8.3 & 6.49 & 201.28 & 300 & 350 & 1300 & 65.87 & 38 & 2900 & 1300 & 2.27 & & 9.56 \\
\hline & & & 平均值 & 8.13 & 1.67 & 48.18 & 116 & 79 & 289 & 21.78 & 252 & 610 & 308 & 0.75 & & 9.08 \\
\hline \multirow{6}{*}{$\begin{array}{l}\text { 尾问 } \\
\text { 盐湖 }\end{array}$} & 湖表 & 10 & 最小值 & 7.7 & 228.11 & 102.2 & 950 & 6850 & $6.70 \times 10^{4}$ & $1.64 \times 10^{3}$ & 470 & $5.19 \times 10^{4}$ & $9.45 \times 10^{4}$ & 22.29 & 4 & 21.30 \\
\hline & 卤水 & & 最大值 & 7.8 & 243.51 & 170.2 & 6370 & $1.05 \times 10^{4}$ & $7.17 \times 10^{4}$ & $1.84 \times 10^{3}$ & 530 & $5.68 \times 10^{4}$ & $1.02 \times 10^{5}$ & 24.22 & & 22.50 \\
\hline & & & 平均值 & 7.76 & 236.45 & 133.58 & 1831 & $9.70 \times 10^{3}$ & $6.91 \times 10^{4}$ & $1.74 \times 10^{3}$ & 507 & $5.53 \times 10^{4}$ & $9.83 \times 10^{4}$ & 23.46 & & 21.78 \\
\hline & 晶间 & 11 & 最小值 & 6.2 & 126.38 & 26.2 & 320 & $1.37 \times 10^{4}$ & $2.41 \times 10^{4}$ & 483.68 & 140 & $1.11 \times 10^{4}$ & $7.13 \times 10^{4}$ & 4.64 & 4 & 23.80 \\
\hline & 卤水 & & 最大值 & 7.8 & 397.61 & 218 & 6820 & $8.12 \times 10^{4}$ & $1.07 \times 10^{5}$ & $1.35 \times 10^{4}$ & 970 & $4.33 \times 10^{4}$ & $2.50 \times 10^{5}$ & 45.83 & & 34.89 \\
\hline & & & 平均值 & 7.21 & 319.08 & 106.08 & 1878 & $3.46 \times 10^{4}$ & $7.45 \times 10^{4}$ & $4.03 \times 10^{3}$ & 549 & $2.94 \times 10^{4}$ & $1.82 \times 10^{5}$ & 34.10 & & 29.70 \\
\hline
\end{tabular}

* 部分数据引自文献 $[9]$.

水化学分析结果表明 (表 1, 图 2) : 河流上游地表水中阳离子以 $\mathrm{Ca}^{2+}$ 和 $\mathrm{Na}^{+}$为主, 占 $\mathrm{TZ}^{+}$的 $74 \%$; 阴离子 以 $\mathrm{HCO}_{3}^{-}$和 $\mathrm{Cl}^{-}$为主, 占 $\mathrm{TZ}^{-}$的 $73 \%$, 水化学类型为 $\mathrm{HCO}_{3} \cdot \mathrm{Cl}-\mathrm{Na} \cdot \mathrm{Ca}$ 型. 中游地表水中阳离子以 $\mathrm{Na}^{+}$为主, 占 $\mathrm{TZ}^{+}$的 $60 \%$ 以上; 阴离子以 $\mathrm{HCO}_{3}^{-}$和 $\mathrm{Cl}^{-}$为主, 二者占 $\mathrm{TZ}^{-}$的 $70 \%$ 以上, 地表水的水化学类型呈 $\mathrm{HCO}_{3} \cdot \mathrm{Cl}_{-} \mathrm{Na}$ 型. 中游地下水中阳离子以 $\mathrm{Na}^{+}$为主, 其离子浓度大于 $\mathrm{TZ}^{+}$的 $50 \%$; 阴离子以 $\mathrm{HCO}_{3}^{-}$和 $\mathrm{SO}_{4}^{2-}$ 为主, 二者离子浓 度大于 $\mathrm{TZ}^{-}$的 $60 \%$, 地下水的水化学类型为 $\mathrm{HCO}_{3} \cdot \mathrm{SO}_{4}-\mathrm{Na}$. 尾问盐湖段湖表卤水中阳离子以 $\mathrm{Na}^{+}$为主, 占 $\mathrm{TZ}^{+}$ 的 76\% ; 阴离子以 $\mathrm{Cl}^{-}$占优势, 占 $\mathrm{TZ}^{-}$的 $70 \%$, 水化学类型呈 $\mathrm{Cl}-\mathrm{Na}$ 型. 晶间卤水中阳离子以 $\mathrm{Na}^{+}$和 $\mathrm{Mg}^{2+}$ 为主, 占 $\mathrm{TZ}^{+}$的 $94 \%$,阴离子以 $\mathrm{Cl}^{-}$占优势, 占 $\mathrm{TZ}^{-}$的 $86 \%$,水化学类型为 $\mathrm{Cl}-\mathrm{Na} \cdot \mathrm{Mg}$ 型.

\section{2 盆地内水体的 $B$ 同位素特征}

水体中 $\mathrm{B}$ 浓度与 $\delta^{11} \mathrm{~B}$ 组成表明: 上游地表水中 $\mathrm{B}$ 浓度范围为 $0.02 \sim 0.43 \mathrm{mg} / \mathrm{L}$, 均值为 $0.13 \mathrm{mg} / \mathrm{L} ; \delta^{11} \mathrm{~B}$ 组成范围为 $6.23 \% 0 \sim 8.03 \%$, 均值为 $7.30 \%$. 中游地表水中 B 浓度范围为 $0.33 \sim 3.49 \mathrm{mg} / \mathrm{L}$, 均值为 1.01 $\mathrm{mg} / \mathrm{L} ; \delta^{11} \mathrm{~B}$ 组成范围为 $15.85 \% 0 \sim 17.14 \%$, 均值为 $16.50 \%$. 中游地下水中 B 浓度范围为 $0.14 \sim 2.27 \mathrm{mg} / \mathrm{L}$, 均 值为 $0.75 \mathrm{mg} / \mathrm{L} ; \delta^{11} \mathrm{~B}$ 组成范围为 $8.05 \% 0 \sim 9.56 \%$, 均值为 $9.08 \%$. 尾问盐湖段湖表卤水中 $\mathrm{B}$ 浓度范围为 $22.29 \sim 24.22 \mathrm{mg} / \mathrm{L}$, 均值为 $23.46 \mathrm{mg} / \mathrm{L} ; \delta^{11} \mathrm{~B}$ 值变化范围为 $21.30 \% 0 \sim 22.50 \%$, 均值为 $21.78 \% 0$; 晶间卤水中 B 浓 度变化范围为 $4.64 \sim 45.83 \mathrm{mg} / \mathrm{L}$, 均值为 $34.10 \mathrm{mg} / \mathrm{L} ; \delta^{11} \mathrm{~B}$ 值变化范围为 $23.80 \% 0 \sim 34.89 \%$, 均值为 $29.70 \%$ 。

\section{4 讨论}

\section{1 盆地内地表水与地下水交换的水化学证据}

在盆地内, 上游河流水体的水化学参数无明显变化, 在出山口附近地表水与地下水发生明显的交换, 故 重点对出山口至盐湖区进行分析. 在河流中游, 地表水和地下水的 $\mathrm{pH}$ 值与上游水体的 $\mathrm{pH}$ 值相近, 呈弱碱 性; 在尾问盐湖段, 由于蒸发浓缩作用较为明显, 晶间卤水的 $\mathrm{pH}$ 值从中性逐渐减小, 特别是远离盐湖卤水的 采样点 (GJJ15-7、GJJ15-8、GJJ15-9) 的 $\mathrm{pH}$ 值呈弱酸性, 而湖表卤水的 $\mathrm{pH}$ 值较为稳定, 无明显变化, 呈中性 


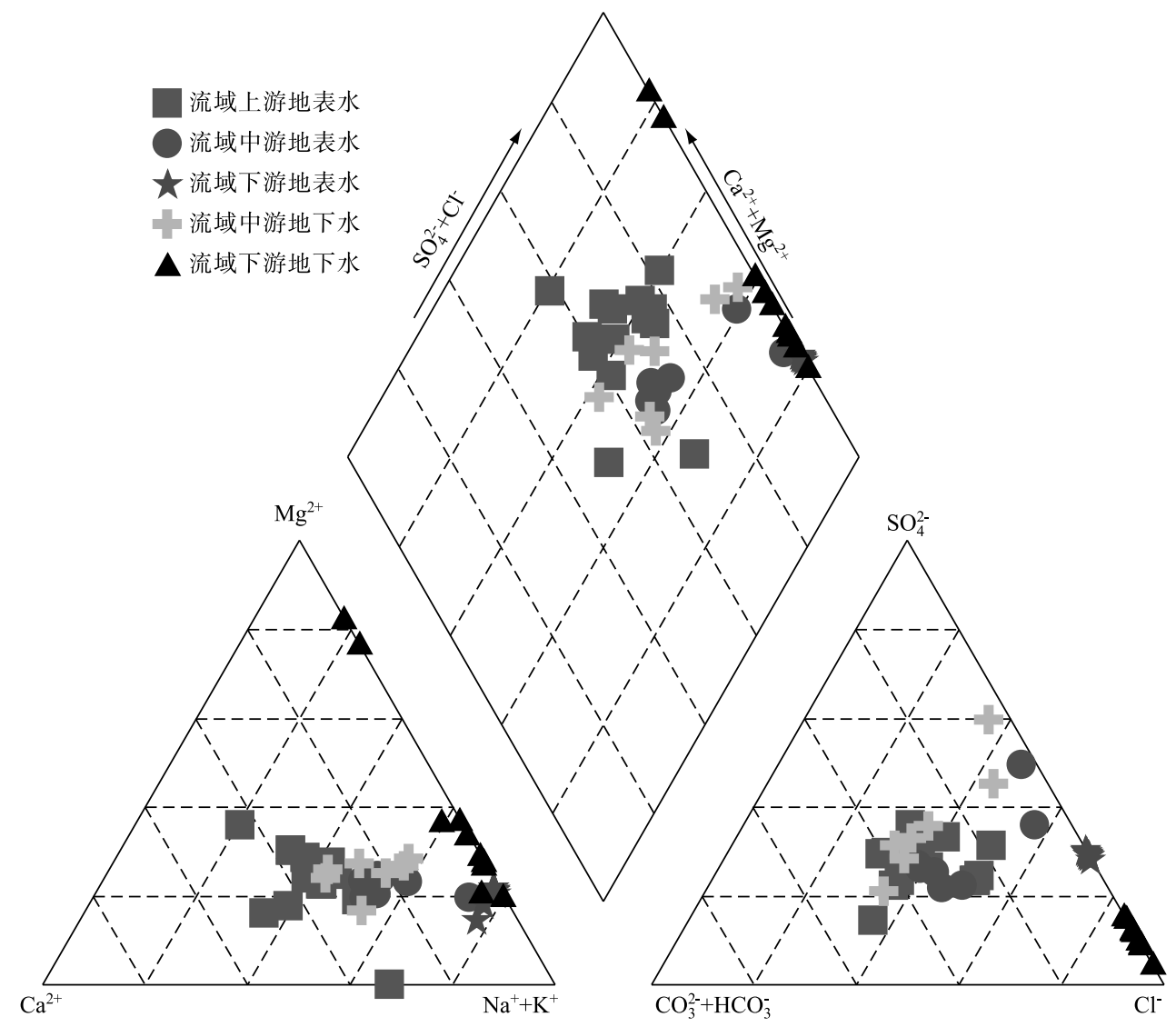

图 2 尔斯库勒盐湖盆地地表水与地下水 Piper 图

Fig. 2 Piper diagram of surface water and groundwater of the Gas Hure Salt Lake Basin

(图 3a).

从盆地水体的 TDS 浓度来看 (图 3b), 上游河水和中游出山口泉水呈低 TDS 特征, 表明上游和中游水体 具有强烈的水交换. 我们在野外也观察到, 出山口附近即使含有芒硝等盐类矿物覆盖, 但水体的 TDS 浓度较 低, 显示微咸水. 在尾问盐湖段, 湖表卤水和晶间卤水的蒸发浓缩作用使水体的 TDS 浓度急剧增大, 但湖表 卤水接受其他水体补给作用,其 TDS 浓度低于晶间卤水.

盆地水体的水化学离子浓度的变化如图 4 所示. 河流上游至中游, 地表水和地下水中离子浓度很低且 较为稳定, 反映地表水和地下水的交换较强; 在尾问盐湖段, 湖表卤水的离子浓度变化较为稳定, 晶间卤水 的离子浓度波动较大, 并且与湖表卤水的变化曲线相交, 特别是 $\mathrm{HCO}_{3}^{-}$浓度和 $\mathrm{Na}^{+}$浓度. 研究表明, 这些离子 来源于高山区和第三系出露的含盐地层的淋滤作用 ${ }^{[11]}$, 如果湖表卤水中具有较高的 $\mathrm{HCO}_{3}^{-}$浓度和较低的 $\mathrm{Na}^{+}$浓度, 说明有其他淡水的补给. 从图 4(c,e) 中可以看出, 在靠近湖表卤水的晶间卤水 (GJJ15-1、GJJ15-2、 GJJ15-3) 和位于干盐滩南部的晶间卤水(GJJ15-8、GJJ15-9) 中 $\mathrm{HCO}_{3}^{-}$浓度高于湖表卤水的浓度,但 GJJ15-8、 GJJ15-9 水体中 $\mathrm{Na}^{+}$浓度却较低,有利地证明了干盐滩南部晶间卤水接受淡水侧向径流补给.

从离子浓度变化趋势不难发现, 尾问盐湖段水体中离子浓度分异明显. 研究表明 ${ }^{[15]}$, 在同一均匀的晶 间卤水层中,当有浅层侧向淡水补给时,由于盐层溶解、固液相转化,卤水的化学组分将发生明显的分异; 而 单纯的蒸发浓缩作用,不会造成明显的分异作用. 我们发现湖表卤水中除了 $\mathrm{Ca}^{2+}$ 和 $\mathrm{SO}_{4}^{2-}$ 浓度大于晶间卤水 的浓度之外(图 $4 \mathrm{a}, \mathrm{g}$ ), 其余离子如 $\mathrm{K}^{+} 、 \mathrm{Mg}^{2+} 、 \mathrm{Cl}^{-}$浓度均变小, 这种现象说明除了具有分异作用外, 晶间卤水 与深部富 $\mathrm{Ca}^{2+}$ 水体之间还发生了掺杂作用, 而在研究区内广泛发育的断裂构造很有可能是深部循环水越流 

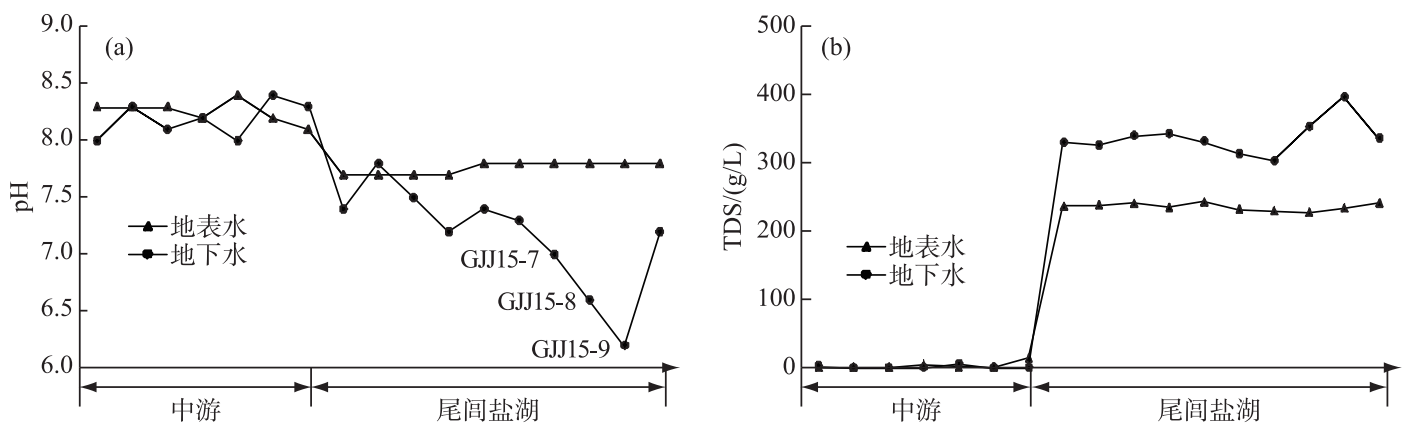

图 3 尔斯库勒盐湖盆地地表水和地下水的 $\mathrm{pH}$ 、TDS 浓度变化

Fig.3 Variation of $\mathrm{pH}$ and TDS concentration of surface water and groundwater in the Gas Hure Salt Lake Basin

补给的通道 ${ }^{[15]}$. 富 $\mathrm{Ca}^{2+}$ 、贫 $\mathrm{SO}_{4}^{2-}$ 的深循环水与晶间卤水混合后, 由于石膏的优先析出, 导致晶间卤水中 $\mathrm{Ca}^{2+}$ 和 $\mathrm{SO}_{4}^{2-}$ 浓度较湖表卤水降低. 另一方面, 离子浓度变化特征显示, 从盐沼带至干盐滩, 蒸发浓缩和化学沉积 分异作用使晶间卤水中 $\mathrm{Mg}^{2+} 、 \mathrm{~K}^{+} 、 \mathrm{Cl}^{-}$浓度大于湖表卤水的浓度(图 $4 \mathrm{~b}, \mathrm{~d}, \mathrm{f}$ ), 而 $\mathrm{SO}_{4}^{2-}$ 呈下降趋势. 五元体系 相图 $\left(\mathrm{K}^{+} 、 \mathrm{Na}^{+} 、 \mathrm{Mg}^{2+} 、 \mathrm{Cl}^{-} 、 \mathrm{SO}_{4}^{2-}-\mathrm{H}_{2} \mathrm{O}\right)$ 研究表明 ${ }^{[15]}$, 湖表卤水和晶间潜卤水组成大部分落在泻利盐相区, 部分 晶间潜卤水组成落在光卤石相区, 与上述结果相吻合. 另外, 晶间卤水 (GJJ15-8、GJJ15-9) 受侧向补给, 在重 力分异作用下将下部较淡的水体挤到上部, 可能促进了固相中矿物的溶解, 从而造成 GJJ15-8、GJJ15-9 水体 中 $\mathrm{Mg}^{2+} 、 \mathrm{~K}^{+} 、 \mathrm{Cl}^{-}$浓度高于其他晶间卤水样品.

\section{2 盆地内地表水与地下水交换的 B 同位素证据}

由于 $\mathrm{B}$ 没有价态变化, B 同位素可视为保守示踪剂, 在源识别上具有独到之处, 往往被用来判别海水人 侵、污染源和水体交换程度等 ${ }^{[16]}$.

$\mathrm{B}$ 同位素在含水介质中的分馏效应与 $\mathrm{B}$ 元素在水溶液中的分子团、溶液的 $\mathrm{pH}$ 和含水介质有关. $\mathrm{B}$ 在水 溶液中主要以分子团 $\mathrm{B}(\mathrm{OH}){ }_{3}^{0}$ 和阴离子 $\mathrm{B}(\mathrm{OH})_{4}^{-}$形式存在, 而 $\mathrm{B}(\mathrm{OH})_{3}^{0}$ 和 $\mathrm{B}(\mathrm{OH})_{4}^{-}$在溶液中的分配比例受溶 液酸碱度所控制, 在低 $\mathrm{pH}$ 值时 $(<7), \mathrm{B}$ 主要以 $\mathrm{B}(\mathrm{OH}){ }_{3}^{0}$ 形式存在; 高 $\mathrm{pH}$ 值时 $(>10)$, 主要以 $\mathrm{B}(\mathrm{OH})_{4}^{-}$形式 存在, 而 ${ }^{11} \mathrm{~B}$ 相对富集在 $\mathrm{B}(\mathrm{OH}){ }_{3}^{0}$ 中并保留在溶液中, ${ }^{10} \mathrm{~B}$ 相对富集在 $\mathrm{B}(\mathrm{OH})_{4}^{-}$中并易进人沉积相中 ${ }^{[17]}$. 在 KLMH 流域,上、中游地表水和地下水具有低 B 浓度和低 B 同位素组成特征, 而在尾问盐湖段水体中具有高 $\mathrm{B}$ 浓度和高 B 同位素组成 (图 $4 \mathrm{~h}$ ). 研究表明, 尾问盐湖段自 $280 \mathrm{ka}$ 以来经历相对湿润-干旱的气候波动和 演化, 沉积物在物性上具有明显差异, 前者以黏土、碎屑沉积为主, 后者以盐类化学沉积为主 ${ }^{[18]}$. 黏土吸附 作用下 $\mathrm{B}$ 同位素会产生比较强烈的分馏作用, 黏土优先吸附 ${ }^{10} \mathrm{~B}$, 从而使水体中富集 ${ }^{11} \mathrm{~B}, \delta^{11} \mathrm{~B}$ 增大 ${ }^{[17]}$.

从图 $4 \mathrm{~h}$ 也发现, 在 KLMH 流域中游地下水的 $\delta^{11} \mathrm{~B}$ 值 $(9.08 \% 0)$ 低于地表水 $(16.50 \%)$, 并且与上游河流 水体的 $\delta^{11} \mathrm{~B}$ 值 $(7.30 \%$ ) 相近, 说明出山口附近地下水 (泉) 来源于上游河流水体. 在尾问盐湖段 (图 $4 \mathrm{~h}$ ), 晶 间卤水的 $\delta^{11} B$ 值 $\left(29.70 \%\right.$ ) 大于湖表卤水的 $\delta^{11} B$ 值 $\left(21.78 \%\right.$ ), 并且晶间卤水的 $\mathrm{B}^{3+}$ 浓度 $(34.10 \mathrm{mg} / \mathrm{L})$ 大于 湖表卤水的 $\mathrm{B}^{3+}$ 浓度 $(23.46 \mathrm{mg} / \mathrm{L})$, 说明在通常情况下, 尾问盐湖段卤水中 $\mathrm{B}^{3+}$ 浓度与 $\mathrm{B}$ 同位素组成呈正相 关. 然而, 晶间卤水 GJJ15-7 中具有较高的 B 同位素值 $\left(34.49 \%\right.$ ) 、较低的 $\mathrm{B}^{3+}$ 浓度值 $(20.94 \mathrm{mg} / \mathrm{L}$ ) 和较低的 $\mathrm{B} / \mathrm{Cl}\left(1.07 \times 10^{-4}\right)$, 结合 $\mathrm{GJJ} 15-7$ 中富 $\mathrm{Ca}^{2+}$ 、贫 $\mathrm{SO}_{4}^{2-}$ 的特征,显示了 $\mathrm{GJJ} 15-7$ 明显具有深源特征.

\section{3 地表水一地下水定量转化关系}

虽然 B 同位素的分馏受较多因素控制 ${ }^{[19]}$, 但 B 同位素仍然可以作为不同水体端元的常用识别手 段 ${ }^{[20-21]}$, 在盐湖卤水补给端元的识别中也有较多的研究 ${ }^{[22-23]}$. 因此, 利用水体混合端元模型 ${ }^{[16]}$ (公式 (1), (2)) 估算了 KLMH 流域地表水与地下水之间的定量转化.

$$
\begin{gathered}
f_{\mathrm{s}}=\frac{\delta_{\mathrm{M}}-\delta_{\mathrm{g}}}{\delta_{\mathrm{s}}-\delta_{\mathrm{g}}} \\
f_{\mathrm{g}}=1-f_{\mathrm{s}}
\end{gathered}
$$



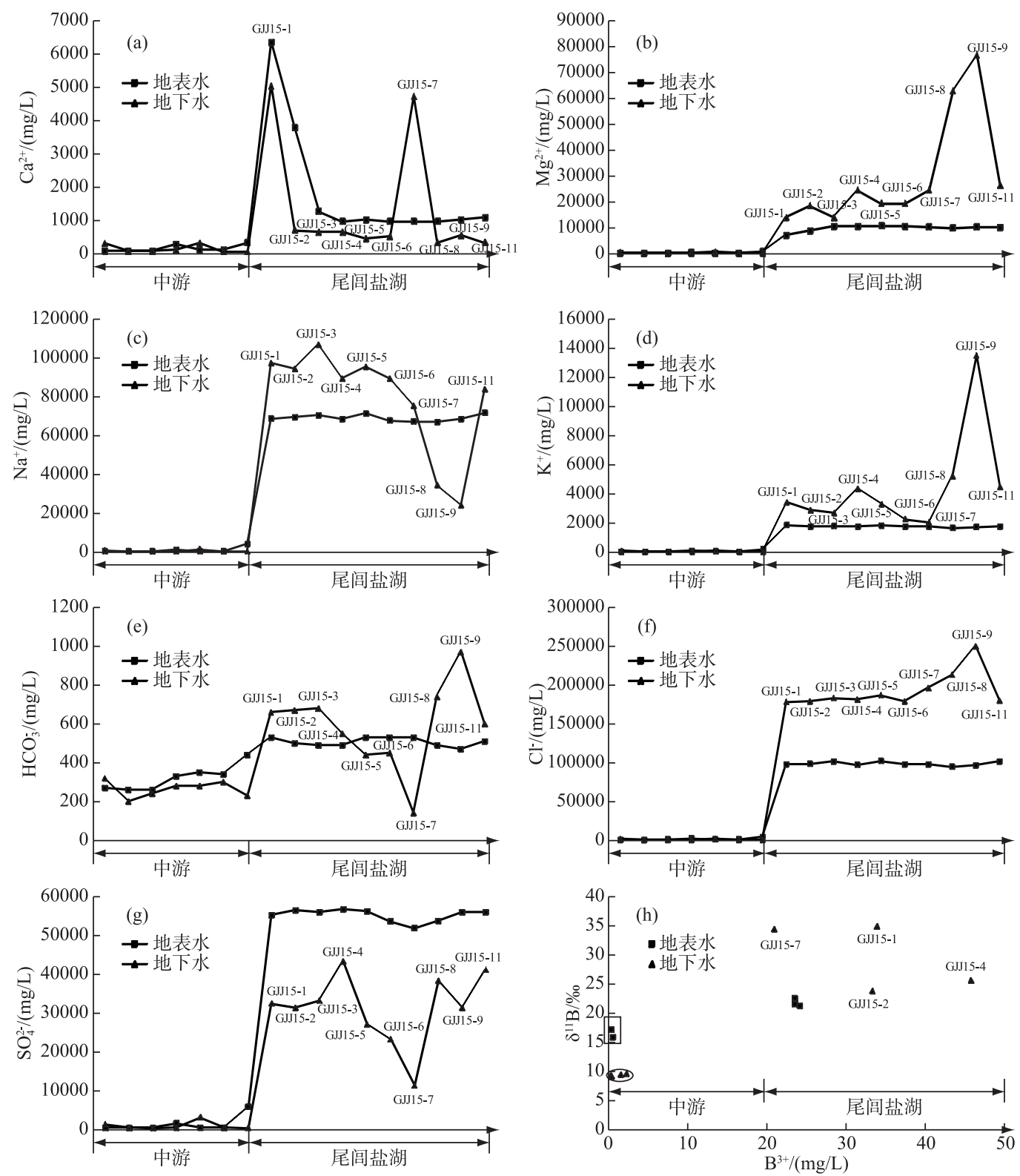

图 4 尔斯库勒盐湖盆地地表水和地下水的离子浓度变化与 $\mathrm{B}$ 同位素组成

Fig.4 Variation of elements concentration and boron isotopic values of surface water and groundwater in the Gas Hure Salt Lake Basin

式中, $\delta_{\mathrm{M}}$ 为混合水同位素组成 $(\% 0), \delta_{\mathrm{s}}$ 为地表水的同位素组成 $(\% 0), \delta_{\mathrm{g}}$ 为地下水的同位素组成 $(\% 0), f_{\mathrm{s}}$ 为混 合水 (盐湖卤水) 中地表水所占的比例 (\%), $f_{\mathrm{g}}$ 为混合水中地下水所占的比例 (\%).

由流域水化学和同位素特征可以看出, 上游段 KLMH 河水和 ATKH 河水通过地表径流,混合后在出山 口转人地下并在流域中游段出露地表, 表明流域上游段地表水完全转人地下.

在中游, 地下水 (取 GJ-1, $\delta_{\mathrm{g}}=8.05 \%$ ) 接受上游地表水 (取 KLMH15-1 KLMH15-10 的均值, $\delta_{\mathrm{s}}=6.97 \%$ ) 和侧向径流 (取 Q15-1 Q15-6 的均值, $\delta_{M}=9.33 \%$ ) 补给, 地表水和侧向径流补给地下水的比例分别占 
$48.8 \%$ 和 $51.2 \%$; 根据监测资料 ${ }^{[13]}, \mathrm{KLMH}$ 与 ATKH 的年均流量分别为 $1.22 \times 10^{8} 、 9.93 \times 10^{7} \mathrm{~m}^{3} / \mathrm{a}$, 由此推断 侧向径流补给年均流量为 $1.13 \times 10^{8} \mathrm{~m}^{3} / \mathrm{a}$, 进一步计算出 ALEH 的年径流补给量为 $1.08 \times 10^{8} \mathrm{~m}^{3} / \mathrm{a}$, 与监测数据 $\left(1.18 \times 10^{8} \mathrm{~m}^{3} / \mathrm{a}\right)^{[13]}$ 基本吻合, 说明上述分析结果可靠.

尾问盐湖段卤水 (取 GHSL15-2,4,7,9 和 GJJ15-2,4 的均值, $\delta_{M}=22.75 \%$ ) 为端元 A 水体 (包括地表水 (取 ALEH-1 $\delta_{s}=17.14 \%$ 和地下水侧向补给, 取 $\delta_{g}=9.33 \%$, 二者均值为 $13.23 \% 0$ ) 和端元 B-深源流体 (取 GJJ-7 的值, $\delta_{g}=34.49 \%$ ) 的混合, 端元 A 和 B 的补给分别占 $55.2 \%$ 和 $44.8 \%$, 这一结果与叶传永利用 ${ }^{234} U{ }^{238} U$ 比值估算的深部来源的补给贡献值 $(10.4 \%)$ 差别较大 ${ }^{[24]}$. 出现这种差别, 主要是与深部水体采样 点数量偏少有关, 还可能与尾问盐湖段沉积物的吸附造成 $\mathrm{B}$ 同位素较大分馏有关. 因此, 在尾问盐湖段利用 B 同位素估算端元混合比及其年补给量是不可靠的. 盆地内地表水和地下水转化示意如图 5 所示.

表 2 尔斯库勒盐湖盆地地表水和地下水之间的转化量

Tab.2 Exchange quantify between surface water and groundwater in Gas Hure Salt Lake Basin

\begin{tabular}{cccccc}
\hline KLMH 流域 & $\delta_{\mathrm{M}}$ & $\delta_{\mathrm{s}}$ & $\delta_{\mathrm{g}}$ & $f_{\mathrm{s}}$ & $f_{\mathrm{g}}$ \\
\hline 上游一中游 & $9.33 \%$ & $6.97 \%$ & $8.05 \%$ & $48.8 \%$ & $51.2 \%$ \\
中游一尾问盐湖段 & $22.75 \% 0$ & $13.23 \% 0$ & $34.49 \% 0$ & $55.2 \%$ & $44.8 \%$ \\
\hline
\end{tabular}

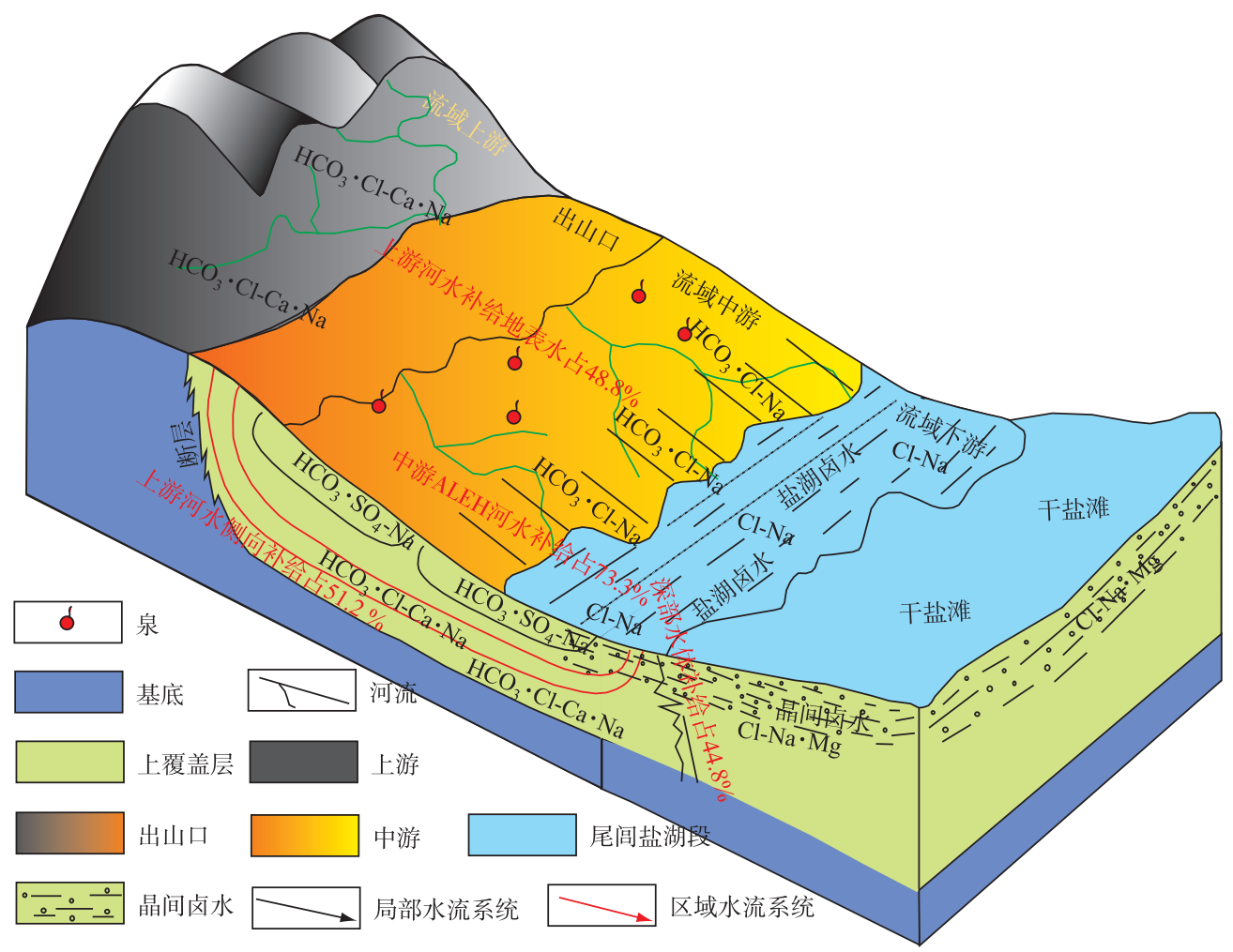

图 5 尔斯库勒盐湖盆地地表水一地下水转化示意图

Fig. 5 The map of surface water and groundwater exchange of the Gas Hure Salt Lake Basin

\section{4 盆地内地表水与地下水中铀的补给通量}

水体作为一种重要的地质营力, 在元素迁移富集或成盐成矿过程中扮演着重要角色. 通过上述地表水一 地下水的定量转化关系, 结合流域内地表水和地下水中铀浓度大小, 利用公式(3)估算流域中常年性河流对 铀的补给通量 (表 3 ). 


$$
T_{\mathrm{U}}=Q \cdot C_{\mathrm{U}} \cdot t
$$

式中, $T_{\mathrm{U}}$ 为铀的补给量 $(\mathrm{t}), Q$ 为河流年平均流量 $\left(\mathrm{m}^{3} / \mathrm{a}\right), C_{\mathrm{U}}$ 为河流水体的平均铀浓度 $(\mathrm{mg} / \mathrm{L}), t$ 为持续补给 时间 (a).

年代学的研究表明 ${ }^{[25-26]}$, ATKH 河流一级阶地为 $6.84 \pm 0.44 \mathrm{ka}$,二级阶地为 $12.58 \pm 0.87 \mathrm{ka}$, 鸭子泉河 (OSL 测年) (为 KLMH 河流的一小支流, 采样期间该河流干涸) 一级阶地为 $5.7 \pm 1.34 \mathrm{ka}$, 二级阶地为 $10.4 \pm$ $1.58 \mathrm{ka}$, 而柴达木盆地盐湖区一级阶地形成年代 (OSL 测年) 为 $7.5 \pm 0.5 \mathrm{ka}$, 二级阶地为 $9.9 \pm 1.7 \mathrm{ka}$, 说明全 新世早期昆仑山地区的气候、构造与这些地区地貌的形成作用具有同步性 ${ }^{[26]}$. 由此可以判断, 至少在 $5.7 \mathrm{ka}$ 以来研究区河流系统与湖泊系统的地貌格局没有重大的变化. 假设从 $5.7 \mathrm{ka}$ 开始, 上游水体对铀运移并最 终在盐湖内得到富集, 则可推断上游水体对铀的持续补给量为 $8.22 \times 10^{3} \mathrm{t}$. 假设在水力运移过程中由于吸附 等原因铀的损失量为 $50 \%{ }^{[5]}$, 最终盐湖卤水中铀的总补给量为 $4.11 \times 10^{3} \mathrm{t}$, 已具备中等规模的铀矿床, 极具 开发利用价值. 但从目前的储量来看 (小于 $500 \mathrm{t}$ ), 尔斯库勒盐湖卤水中并无如此规模的铀矿床, 推断在中 游地表水一地下水交换过程中由于含水层环境的变化, 或铀与不同界面之间发生复杂的生物地球化学作用 导致沉积了较大规模的铀矿床. 这一点我们从流域沉积物中铀浓度也发现, 除了流域上游的富铀岩石 (花岗 岩) 中铀含量 $(3.32 \sim 7.26 \mu \mathrm{g} / \mathrm{g})$ 较高之外, 中游和祁漫塔格山前的局部黏土沉积物和局部还原带中铀浓度 $(2.35 \sim 8.78 \mu \mathrm{g} / \mathrm{g})$ 也很高 ${ }^{[10]}$, 说明铀在迁移过程中在此地段发生富集, 具有很好的找矿意义.

表 3 库拉木勒克萨伊河流域地表水和地下水对铀的补给量

Tab.3 Uranium quantify by surface water and groundwater recharge of Kulamuleksay River

\begin{tabular}{ccccc}
\hline 河流 & $Q /\left(\mathrm{m}^{3} / \mathrm{a}\right)$ & $C_{\mathrm{U}} /(\mathrm{mg} / \mathrm{L})$ & $T_{\mathrm{U}} / \mathrm{t}$ & 持续补给时间 $/ \mathrm{a}$ \\
\hline KLMH & $1.22 \times 10^{8}$ & 5.70 & $3.96 \times 10^{3}$ & 5700 \\
ATKH & $9.93 \times 10^{7}$ & 7.53 & $4.26 \times 10^{3}$ & 5700 \\
总计(扣除损失量) & & & $4.11 \times 10^{3}$ & \\
\hline
\end{tabular}

\section{5 结论}

通过传统的水化学法结合 B 同位素技术识别了尔斯库勒盐湖盆地内地表水和地下水之间的定量转化 关系, 并推断了铀的补给通量, 得出以下结论:

1 ) 河流上游至下游地表水化学类型分别为 $\mathrm{HCO}_{3} \cdot \mathrm{Cl}-\mathrm{Na} \cdot \mathrm{Ca}$ 型、 $\mathrm{HCO}_{3} \cdot \mathrm{Cl}-\mathrm{Na}$ 型、 $\mathrm{Cl}-\mathrm{Na}$ 型; 地下水化学类 型分别为 $\mathrm{HCO}_{3} \cdot \mathrm{SO}_{4}-\mathrm{Na}$ 型和 $\mathrm{Cl}-\mathrm{Na} \cdot \mathrm{Mg}$ 型, 离子浓度的这种分异现象受蒸发浓缩、重力分异和掺杂作用的 控制.

2) 盆地内地表水与地下水之间发生了两次交换, 中游地下水以泉的形式补给地表水,地表水人渗补给 地下水; 在尾问盐湖段, ALEH 河水通过地表径流补给盐湖, 深部水体补给盐湖卤水. 其中, 上游水体对地下 水的补给率为 $51.2 \%$, 年均补给量为 $1.13 \times 10^{8} \mathrm{~m}^{3} / \mathrm{a}$; 上游水体对地表水的补给率为 $48.8 \%$, 年均补给量为 $1.08 \times 10^{8} \mathrm{~m}^{3} / \mathrm{a}$. 中游地表水和侧向补给盐湖卤水的补给率占 $55.2 \%$; 深部水体补给盐湖卤水的补给率占 $44.8 \%$.

3 ) 至少从 $5.7 \mathrm{ka}$ 以来, 上游河流对铀的补给通量为 $4.11 \times 10^{3} \mathrm{t}$. 在湖积平原黏土沉积带或祁漫塔格山前 局部还原带可能赋存较大规模的铀矿床.

\section{6 参考文献}

[ 1 ] Wang WK, Li JT, Wang Z et al. Evolution of the relationship between river and groundwater and several scientific problems. Journal of Jilin University: Earth Science Edition, 2007, 37(2): 231-238. [王文科, 李俊亭, 王钊等. 河流与地 下水关系的演化及若干科学问题. 吉林大学学报:地球科学版, 2007, 37(2): 231-238.]

[ 2 ] Zhu JF, Liu YY, Zhang SA et al. Review on the research of surface water and groundwater interactions. China Environmental Science, 2017, 37(8):3002-3010. [ 朱金峰, 刘悦忆, 章树安等. 地表水与地下水相互作用研究进展. 中国 环境科学, 2017, 37 (8): 3002-3010.] 
[ 3 ] Wu C. Disscussion on Qinghai salt lake resources exploitation and its industry.Qinghai Territory Strategy, 2002, ( S1): 32-39. [ 吴蝉. 青海盐湖资源开发及其产业探讨. 青海国土经略, 2002，(S1) : 32-39.]

[ 4 ] Han JB, Xu JX, An Z et al. Research advance of the salt lake underground brine extration technology. Journal of Salt Lake Research, 2015, 23(1) : 67-72. [ 韩积斌, 许建新, 安朝等. 盐湖地下卤水的开采技术及其展望. 盐湖研究, 2015, $23(1): 67-72$.]

[ 5 ] Yu JQ, Gao CL, Cheng AY et al. Geomorphic, hydroclimatic and hydrothermal controls on the formation of lithium brine deposits in the Qaidam Basin, northern Tibetan Plateau, China. Ore Geology Reviews, 2013, 50: 171-183.

[ 6 ] Zhan DP, Yu JQ, Gao CL et al. Hydrogeochemical conditions and lithium brine formation in the four salt lakes of Qaidam Basin. J Lake Sci, 2010, 22 (5) : 783-792. DOI: 10.18307/2010.0522. [ 展大鹏, 余俊清, 高春亮等. 柴达木盆地四盐 湖卤水锂资源形成的水文地球化学条件. 湖泊科学, 2010, 22(5): 783-792.]

[ 7 ] Chen ZY, Huang Y, E CY. Analysis on development and utilization of groundwater resources in Nalinggele Watershed. Journal of Qinghai Normal University: Natural Science, 2018, 34(2) : 48-54. [陈宗颜, 黄勇, 鄂崇毅. 那陵格勒河流 域地下水资源开发利用方案分析. 青海师范大学学报:自然科学版, 2018, 34(2) : 48-54.]

[ 8 ] Wang YH, Wang WK, Duan L et al. Study on dynamic of groundwater in alluvial-pluvial fan zone in front of mountain of Golmud River basin. Journal of Water Resources \& Water Engineering, 2014, 25(1) : 133-136. [王宇航, 王文科, 段砧 等. 格尔木河流域山前冲洪积扇地下水动态研究. 水资源与水工程学报, 2014, 25(1) : 133-136.]

[ 9 ] Han JB, Jiang HC, Xu JX et al. Hydraulic connection affects uranium distribution in the Gas Hure salt lake, Qaidam Basin, China. Environmental Science and Pollution Research, 2018, 25(5) : 4881-4895.

[10] Han JB. Migration and enrichment of high concentration uranium in the hydrological system of Gas Hure Salt Lake, Qaidam Basin [Dissertation]. Wuhan: China University of Geosciences, 2018. [ 韩积斌. 尔斯库勒盐湖盆地水文系统中高浓度 铀的迁移富集行为 [学位论文]. 武汉: 中国地质大学, 2018.]

[11] Han JB, Xu JX, Wang GQ et al. The material sources and it's hydraulic migration in the Gas Hure salt lake, Qaidam Basin. J Lake Sci, 2017, 29(6) : 1551-1560. DOI: 10.18307/2017.0627. [ 韩积斌, 许建新, 王国强等. 柴达木盆地尔斯 库勒盐湖区成盐物质的来源与水力迁移作用. 湖泊科学, 2017, 29(6) : 1551-1560.]

[12] Han JB, Xu JX, Hai QY et al. Simulation of $\mathrm{CO}_{2}$-brine-rock interaction of Gas Hure salt lake in Qaidam Basin. Uranium Geology, 2016, 32(1) : 54-59. [ 韩积斌, 许建新, 海擎宇等. 尔斯库勒盐湖中 $\mathrm{CO}_{2}$-卤水-盐岩相互作用模拟研究. 铀矿地质, 2016, 32(1): 54-59.]

[13] Rong GZ, Tian XB, Li YP et al. Potash detailed survey report in the Gas Hure salt lake, Qaidam Basin. Qinghai: Qinghai Geological Survey Institute, 2003. [ 荣光忠, 田希宝, 李云平等. 青海省茫崖镇尔斯库勒钾矿详查报告. 青海省地质 调查院, 2003.]

[14] Zhang T, Han WX, Fang XM et al. Intensified tectonic deformation and uplift of the Altyn Tagh range recorded by rock magnetism and growth strata studies of the western Qaidam Basin, NE Tibetan Plateau. Global and Planetary Change, 2016, 137: 54-68.

[15] Wei XJ, Shao CD, Wang ML et al eds. Material composition, sedimentary characteristics and formation conditions of potash-bearing saline lakes in the western of Qaidam Basin. Beijing: Geological Publishing House, 1995. [魏新俊, 邵长铎, 王弭力等. 柴达木盆地西部富钾盐湖物质组分、沉积特征及形成条件研究. 北京: 地质出版社, 1995.]

[16] Gu WZ, Pang ZH, Wang QJ et al eds. Isotope Hydrology. Beijing: Science Press, 2011. [顾慰祖, 庞忠和, 王全九等. 同位素水文学. 北京: 科学出版社, 2011.]

[17] Xiao YK, Wang L. The effect of $\mathrm{pH}$ and temperature on the isotopic fractionation of boron between saline brine and sediments. Chemical Geology, 2001, 171(3/4) : 253-261.

[18] Ye CY, Wang ZM, Zhao SQ et al. Sedimentary characteristics since 280 ka B.P. in Gas Hure salt lake in western Qaidam Basin. Acta Sedimentologica Sinica, 2014, 32(1) : 85-92. [叶传永, 王志明, 赵世勤等. 柴达木盆地西部尔斯库勒盐 湖 $280 \mathrm{Ka}$ 以来沉积特征. 沉积学报, 2014, 32(1): 85-92.]

[19] Xiao YK, Shirodkar PV, Liu WG et al. Study on boron isotope geochemistry of salt lake in Qaidam Basin. Advances in Natural Science, 1999, 9(7): 38-44. [肖应凯, Shirodkar PV, 刘卫国等. 青海柴达木盆地盐湖硼同位素地球化学研究. 自然科学进展, $1999,9(7): 38-44$. $]$

[20] Cary L, Casanova J, Gaaloul N et al. Combining boron isotopes and carbamazepine to trace sewage in salinized groundwater: A case study in Cap Bon, Tunisia. Applied Geochemistry, 2013, 34: 126-139. 
[21] Vengosh A, Kloppmann W, Marei A et al. Sources of salinity and boron in the Gaza strip: Natural contaminant flow in the southern Mediterranean coastal aquifer. Water Resources Research, 2005, 41(1) : 1-19.

[22] Han FQ, Chen YJ, Han JL et al. Boron isotope geochemical characteristics and its geological significances of high salinity salt springs in Nangqian Basin, Qinghai Province, China. Acta Geoscientica Sinica, 2016, 37(6) : 723-732.

[23] Fan QS, Ma YQ, Cheng HD et al. Boron occurrence in halite and boron isotope geochemistry of halite in the Qarhan Salt Lake, western China. Sedimentary Geology, 2015, 322 : 34-42.

[24] Ye CY. Distribution and enrichment mechanism of uranium in the brine and sediments of Gas Hure salt lake [ Dissertation]. Beijing: Beijing Research Institute of Uranium Geology, 2013 [叶传永. 尔斯库勒盐湖卤水与沉积物中铀的分 布及富集机理 [学位论文]. 北京: 核工业北京地质研究院, 2013.]

[25] Wang A, Smith JA, Wang GC et al. Late Quaternary river terrace sequences in the eastern Kunlun Range, northern Tibet: A combined record of climatic change and surface uplift. Journal of Asian Earth Sciences, 2009, 34(4) : 532-543.

[26] Zhao ZM, Li RS. Evolutionary characteristics of river and lake terraces in different areas of the northern Qinghai-Tibet Plateau. Geological Bulletin of China, 2006, 25(1/2): 221-225. [赵振明, 李荣社. 青藏高原北部不同地区河流和湖岸 阶地的演化特征. 地质通报, 2006, 25(1/2): 221-225.] 